\title{
GAMIFICAÇÃO COMO ESTRATÉGIA NA CONSTRUÇÃO DE OBJETO DE APRENDIZAGEM EM HISTÓRIA EM QUADRINHOS
}

\author{
GAMIFICATION AS A STRATEGY IN THE CONSTRUCTION OF COMICS \\ LEARNING OBJECTS
}

Raul Inácio Busarello

\begin{abstract}
Objeto de Aprendizagem, Gamificação, Histórias em Quadrinhos Este capítulo parte da pesquisa sobre a identificação de quais aspectos de um objeto de aprendizagem, com base em histórias em quadrinhos hipermídia gamificado, são eficientes para a motivação e geração de conhecimento dos alunos. O objetivo é apresentar a construção de objeto de aprendizagem citado, salientando as estratégias de gamificação adotadas no projeto. Dessa forma, apresenta a estrutura do artefato criado, salientando os objetos de aprendizagem que o compõem, além das estratégias de gamificação utilizadas. Como resultado identifica-se que o artefato é composto por três níveis de objetos de aprendizagem, contemplando uma fragmentação de dezoito objetos menores. Quanto aos tópicos de gamificação, as estratégias buscam estimular as motivações intrínsecas dos alunos, investindo nos aspectos cognitivos, emocionais e sociais dos estudantes.
\end{abstract}

Palabras clave: Objeto de Aprendizagem, Gamificação, Histórias em Quadrinhos

This chapter starts from the research on identifying aspects of a learning object, based on hypermedia comic, are efficient for motivation and generation of students' knowledge. The objective is to present the construction of learning object mentioned, highlighting the gamification strategies adopted in the project. In this way, it presents the structure of the artifact created, emphasizing the learning objects that compose it, besides the gamification strategies used. As a result it is identified that the artifact is composed of three levels oflearning objects, contemplating a fragmentation of eighteen smaller objects. As for the topics of gamification, the strategies seek to stimulate the intrinsic motivations of the students, investing in the cognitive, emotional and social aspects of the students.

Keywords: Learning Object, Gamification, Comics 


\section{Introducão}

Compreende-se que através da gamificação é possível adaptar o conteúdo de um domínio específico para diferentes perfis de alunos, uma vez que, de acordo com Kapp (2012), é possível a elaboração de diferentes caminhos para a aprendizagem, além de se permitir diferentes métodos para o sujeito adquirir o conhecimento (BUSARELLO, 2016). No contexto da gamificação o conhecimento deve ser externo e, de forma parcial, comum aos alunos. O estudante, por sua vez, é o agente mais importante no processo de aprendizagem, uma vez que a escolha do percurso para o conhecimento parte dele. Para isso o ambiente de aprendizagem deve ter como base traços dos alunos e prever suas atitudes. O professor ou o objeto de aprendizagem é o agente promotor dos níveis de engajamento no processo, influenciando a motivação do aluno no ambiente. Neste sentido, a gamificação é vista como uma abordagem para acelerar a curva de experiência do sujeito, favorecendo o aprendizado de conteúdos e sistemas complexos.

Para Kapp (2012) a gamificação promove um nível de interesse e uma nova maneira de agrupar um conjunto de elementos psicológicos em um ambiente promotor de engajamento e motivação. Hanus e Fox (2015) compreendem que em um contexto educacional, a gamificação pode ser utilizada de várias de formas, incluindo o uso de narrativas, para alterar o contexto de uma atividade rotineira e incentivar o comportamento dos alunos. Isso favorece que os alunos possam apreender e realizar tarefas, antes tediosas, de uma forma nova e motivada. Além disso, De-Marcus (2014) salientam o potencial da gamificação em processos educacionais onde encontram-se, com frequência, alunos desmotivados nas atividades de aprendizagem. Uma das bases da gamificação é a utilização de elementos de jogos em contextos que não sejam os de jogos, nesse sentido, Amory et al. (1999) identificam que estratégias baseadas em jogos contribuem nas práticas de aprendizagem pois combinam elementos divertidos com design instrucional, além de sistemas motivacionais e interatividade.

Todavia, Busarello et al. (2014) salienta que o desafio está em identificar quais aspectos da gamificação podem ser utilizados na construção de objetos de aprendizagem motivadores e acessíveis. Neste contexto, o foco deste artigo parte da investigação de Busarello (2016) sobre quais aspectos de um objeto de aprendizagem, com base em histórias em quadrinhos hipermídia e construído com base em conceitos de gamificação, são eficientes para a motivação e geração de conhecimento para alunos surdos. A premissa é que a incorporação de mecanismos de gamificação em um objeto de aprendizagem tem o potencial de agregar no processo de motivação e interação do estudante favorecendo assim na sua geração de conhecimento. Neste caso, parte-se dos conceitos de Zichermann e Cunningham (2011) e Vianna et al. (2013), onde a gamificação é vista como uma sistemática de utilização de elementos de jogos, em contextos fora do jogo, para a resolução de problemas. Apresentando o potencial de elevar ou manter dos níveis de engajamento, através do estímulo a motivação intrínseca do sujeito. Para isso, Busarello (2016) salienta que a gamificação utiliza cenários lúdicos para simulação e exploração de fenômenos com objetivos extrínsecos, apoiados em elementos utilizados e criados em jogos. Em se tratando de um objeto de aprendizagem em quadrinhos, McCloud (2006) identifica que o conceito de quadrinhos hipermídia abrange uma série de possibilidades que podem ser implantadas de diversas formas na história, permitindo, de acordo com Busarello (2016) gamificar esta mídia. Isso, de acordo com a compreensão de Macedo (2010) em que um objeto de aprendizagem pode ser qualquer conteúdo midiático, com formatos digitais ou analógicos, desde que utilizado para fins educacionais e desde que seja um objeto bem definido e mensurável.

Neste contexto, o objetivo deste capítulo é apresentar a construção de objeto de aprendizagem em quadrinhos gamificados, proposto por Busarello (2016), salientando as estratégias de gamificação adotadas no projeto. Está dividi em quatro seções, onde a primeira apresenta a estrutura do artefato criado; a segunda situa os objetos de aprendizagem no interior o artefato criado; a terceira apresenta as estratégias de gamificação utilizadas para a construção do objeto de aprendizagem; e a quarta as considerações sobre a pesquisa. 


\section{Objeto de Aprendizagem em História em Quadrinhos Hipermídia Gamificado}

O objeto de aprendizagem criado é um artefato on-line, com base em uma ficção em história em quadrinhos hipermídia, que contempla na sua dinâmica conceitos de gamificação, e que objetiva o ensino de conceitos do domínio de Sólidos. Basicamente é uma história de humor e aventura que narra a trajetória de três piratas em busca de um baú de tesouro. Os conceitos do domínio de sólidos estão embutidos em incidentes na história e em links no decorrer do objeto. Em incidentes essenciais da história, são inseridos exercícios, que devem ser resolvidos pelos personagens e alunos durante a condução da história.

Com base em Busarello (2011) e Busarello et al. (2014), o objeto de aprendizagem é uma história em quadrinhos, possui características de navegação hipermídia e possibilidade de leitura não linear entre conjuntos de quadros; links com acesso para a visualização de dados e histórias paralelas; além da possibilidade de ação direta do leitor na resolução de desafios, o que leva a diferentes desfechos na trama. Aborda o conceito de Sólidos, tópico da disciplina de Geometria Descritiva. Além disso, uma série de mecânicas provenientes dos jogos são utilizadas como recurso em artefatos gamificados. Dessa forma, na criação da história são exploradas as mecânicas dos jogos que melhor se adequaram ao propósito de utilização no objeto de aprendizagem. As mecânicas envolvem a dinâmica de navegação pelo objeto, além de aspectos da construção da própria história.

Zichermann e Cunningham (2011) salientam que aspectos de diversão no jogo envolvem a exploração de um universo ficcional e as emoções do jogador durante a experiência: o primeiro elemento é abordado na ação direta que o aluno realiza durante a história, através de links e resolução de problemas durante a narrativa; o segundo tópico está diretamente ligado ao desenrolar da história. Para toda ação do aluno haverá uma reação na história. No decorrer da interação do aluno, blocos da história vão sendo construídos por caminhos pré-definidos. Como por exemplo, ao passo que o aluno acerta a resposta de um exercício, também o personagem contempla um determinado desafio com sucesso, influenciando na sua jornada. Caso contrário, o personagem é colocado em situações de risco e suspense iminentes. Dessa forma, a pressão que o personagem sente no decorrer da jornada é transmitida ao aluno através do processo de imersão e agência na história hipermídia (MURRAY, 2003).

Collantes (2013) define que as ações tomadas pelo jogador durante o desenrolar do sistema são influenciadas pelo objetivo final do jogo. O mesmo se aplica à gamificação. Estima-se que conhecendo a necessidade dramática dos personagens, no primeiro ato da história (FIELD, 2009), os alunos saberão aquilo que devem buscar na história. Para Li, Grossman e Fitzmarurice (2012) apresentar objetivos claros possibilita o envolvimento do jogador ao sistema, uma vez que facilita o entendimento daquilo que deve ter que ser feito. Dessa forma, não apenas o objetivo final da história está colocado de forma clara, como cada passo que deve ser tomado durante a mesma. Como já utilizado por Busarello (2011), o conteúdo de geometria descritiva está inserido como elemento da trama, de forma que as ações executadas pelos personagens e, consequentemente, pelos alunos leitores, terão como parâmetro o conhecimento de Sólidos aprendido durante a própria condução da narrativa

Li, Grossman e Fitzmarurice (2012) entendem que a utilização de Fantasia no processo de aprendizagem favorece a motivação e engajamento do aluno, desta forma, o tema da história criada recai sobre os gêneros de humor e aventura, apresentando a trama de três piratas em busca de um tesouro. Para isso os personagens enfrentam vários enigmas que envolvem os conceitos sobre Sólidos. A escolha por esse tipo de abordagem busca tornar as experiências dos alunos emocionantes, uma vez que estimula seu imaginário através de situações que não estão extrinsecamente presentes. Seguindo os conceitos de Garris, Ahlers e Driskell (2002), parte do domínio de Sólidos segue os conceitos de Fantasia Endógena, onde tópicos do conhecimento de geometria descritiva estão colocados dentro da trama, como por exemplo a descoberta do Capitão Pirata de que o mapa do tesouro é na verdade a planificação do sólido da ilha. Para auxiliar no processo de aprendizagem, e contando com a motivação da narrativa, o conteúdo de domínio dos links, segue o conceito de Fantasia Exógena.

O desenvolvimento do artefato segue o conceito de Nunes et al. (2011), em que o caráter não linear na construção de objetos de aprendizagem hipermídia, indica que o aluno tem uma única entrada e única saída do objeto, mas com várias possibilidades de links e atividades em seu interior. A saída com sucesso é aquela que passa pela resposta do aluno com retorno positivo ao sistema, durante a avaliação final. Dentro das características dos jogos Vianna et al. (2013) estabelecem parâmetros para as regras básicas de navegação no objeto, em que a interação é feita entre os quadros, links para o domínio de sólidos e pelas continuações possíveis através dos resultados das atividades. De acordo com Craveirinha e Roque (2010) uma narrativa interativa deve ser estruturada de forma que possibilite ao usuário certa liberdade de escolhas pautadas pelas regras do ambiente e que possibilite a impressão de controle de construção da história.

De acordo com a figura 1, cada retângulo corresponde a uma página do objeto, que suporta de um a três 
quadros da história. As setas apresentam as possibilidades de navegação do usuário. Nos quadros da área em azul, encontram-se os conteúdos do domínio, que apresentam prioritariamente informações sobre $o$ conceito de sólidos. O conteúdo inserido nas áreas em amarelo corresponde as avaliações de conhecimento dentro do objeto. Servem não apenas para acompanhar o aprendizado do aluno, mas também como forma de navegação da história. Todas as avaliações levam a três possíveis caminhos, isso porque cada questão apresenta três alternativas objetivas ao aluno. Se a reposta for correta ele é remedido a continuação da história e segue a trama. Entretanto, se a resposta for incorreta os personagens são levados a situações conflituosas, o que sugere ao aluno refazer o exercício.

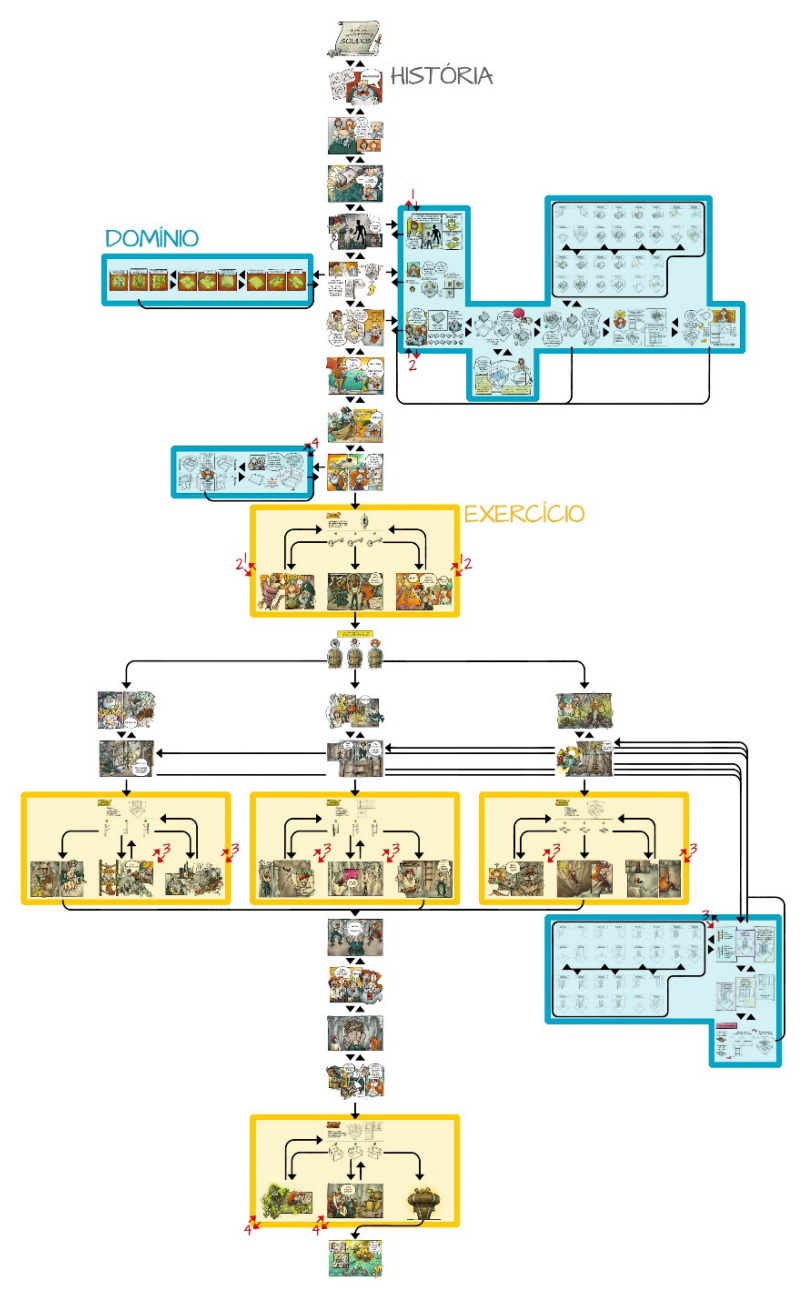

Fig. 1 - Estrutura do objeto de aprendizagem em história em quadrinhos hipermídia gamificado. Fonte: Busarello (2016).

Em grande parte da história o aluno acompanha a trama do grupo de piratas. Entretanto, em determinado momento, o mesmo tem a possibilidade de acompanhar a jornada de apenas um dos piratas. Identifica-se que logo após o primeiro exercício os quadros se dividem em três tramas secundárias, possibilitando ao aluno acompanhar a trajetória de um personagem específico da história. Este as- pecto indica que o leitor pode visualizar um mesmo tema através de diferentes pontos de vista, além de acompanhar o conteúdo através do personagem que melhor se identificar. Do ponto de vista da gamificação, Schimtz, Klemke e Specht (2012) entendem que no contexto de aprendizagem, agentes como personagens têm efeito direto no desenvolvimento do aluno. Por isso a trama apresenta três persona- 
gens com personalidades e caracterização distintas: o Capitão Pirata, um velho ranzinza e agente da ação da história; a Jovem Pirata, uma garota esperta e estudiosa; e o Pirata, um homem destemido e leal. Propositalmente não foram dados nomes aos piratas. A utilização de diferentes personagens na história em quadrinhos hipermidiática vai de encontro à categoria estética transformação apresentada por Murray (2003), na qual o indivíduo tem a capacidade de se transformar em cada um dos três personagens. Pela capacidade de multilinearidade da narrativa, o aluno, mesmo tendo a opção de seguir um personagem específico, também poderá retornar e acompanhar a jornada dos outros dois, de forma paralela.

\section{Os Objetos de Aprendizagem no Interior do Artefato Criado}

Macedo (2010) identifica que um objeto de aprendizagem pode ser qualquer artefato midiático, desde que contribua para a aprendizagem de algum domínio e que possa ser reutilizável. Além disso, é caracterizado como menos reutilizável quando mais contextualizado for seu conteúdo do objeto. Corroborando com a autora, Wiley (2000) cita que um objeto de aprendizagem deve compor estruturas básicas, que podem ser associadas a outras, ou decompostas para a produção de outros objetos. $\mathrm{O}$ objeto deve permitir a interação, favorecendo ao aluno a reflexão e a formação de novos conceitos. Para Mcgreal e Elliot (2004) objetos de aprendizagem podem ser agregados a outros propósitos educacionais, tornando-os assim um componente, ou módulo, de um objeto maior e mais complexo. Neste contexto, Busarello e Ulbricht (2014) compreendem que a história em quadrinhos gamificada criada, por apresentar uma estrutura de navegação não linear entre blocos de quadros, permite a movimentação do aluno entre os conteúdos de domínio e dos exercícios, possibilitando que a junção de partes de objeto crie novos objetos.

O objeto sobre Sólidos apresenta os exercícios como parte integrante da história, tornando as respostas e interação do aluno fundamentais para a própria construção do enredo e aprendizagem. O objeto é constituído em três níveis específicos: o primeiro além de apresentar o início da narrativa ficcional é composto por quatro diferentes links com conteúdo do domínio e fechando em um exercício; o segundo com a possibilidade de se acompanhar três diferentes confrontos da história, e com isso, três exercícios diferentes e diferentes acessos ao conteúdo instrucional; e a terceira parte, que apresenta o desfecho da história e mais um exercício.
De acordo com Macedo (2010) um objeto de aprendizagem deve conter uma forma de avaliar ou acompanhar o desenvolvimento do estudante. No artefato criado, este tópico está representado nos cinco exercícios ao longo dos quadrinhos. Neste caso, constata-se que o primeiro nível de granulação do objeto é estrutura em cinco blocos que contemplam além de conteúdo do domínio também as avaliações. Entretanto, com a possibilidade de visualização não linear, é possível que os exercícios sejam acessados de outros pontos do objeto. Desta forma, os cinco exercícios podem contemplar a visualização da aprendizagem de objetos de aprendizagem menores no artefato. Assim, estrutura-se o segundo nível de granulação do objeto, que de forma geral, abordam pontualmente o domínio de sólidos.

Considerando a fantasia endógena, os quadros 4,5 e 6, da figura 1, formam um objeto de aprendizagem, pois contextualizam base para o conceito de projeção, além de explorar a formação da épura em um triedro, e a construção de um sólido a partir disso. Como terceiro nível de granulação, este objeto ainda é divido em três partes básicas , onde cada conjunto de quadros pode ser utilizado em contextos instrucionais específicos.

Os dois primeiros objetos de aprendizagem, considerados fantasia exógena - quadros 4 e 5 -, abordam respectivamente a conceituação de Projeção Cilíndrica, mostrando a diferença entre Ortogonal e Oblíqua e a exemplificação de Épura.

O objeto de aprendizagem que apresenta a exemplificação da construção de um triedro, através de materiais do dia a dia, também pode ser dividido em duas partes básicas: a primeira que aborda a construção dos planos e a segunda a aplicação de um sólido no triedro - quadros 6 e 7.

O terceiro objeto de aprendizagem em fantasia exógena do artefato, apresenta o conceito do domínio de Sólidos e possui maior granulação e complexidade. $\mathrm{O}$ objeto contextualiza as diferentes vistas que um sólido pode ter, além de sua aplicação em um triedro, e sua planificação em épura. Além disso, possui dois acessos a conteúdos que abordam a construção dos segmentos de retas entre o sólido e o plano, e a exploração pelo aluno de vários aspectos de um sólido aplicado em triedro. Esse objeto se divide em seis objetos de aprendizagem menores, básicos. Quatro na linha principal - quadros 8 a 11 -, onde o primeiro explora a visualidade do sólido; o segundo a aplicação e projeções do sólido nos planos do triedro; e o terceiro e quarto que são formas redundantes de entendem a relação entre épura, triedro e sólido. Ainda há dois outros objetos acessados por links. O primeiro, acessado no segundo quadro, que explora o conceito de segmento de reta na projeção cilíndrica ortogonal - quadro 12; e o segundo que possibilita ao aluno visualizar e explorar a planificação do sólido em um triedro - quadro 13 
Neste o estudante pode selecionar visualizar o sólido, os segmentos de reta e as projeções, em cada um ou em todos os planos.

O sexto objeto de aprendizagem de segundo nível do artefato apresenta um exemplo mais avançado de sólido. De forma geral, explora uma outra visão do sólido que vem sendo trabalhado nos outros objetos. Esse objeto se subdivide em duas partes básicas, onde a primeira identifica a posição do sólido com relação a suas projeções nos planos, e a segunda explora as projeções no triedro e épura. Como pode ser visto nos quadros 14 e 15 da figura 1.

O sétimo e último objeto do artefato está localizado na segunda parte da história e está relacionado com três diferentes exercícios. Este artefato é uma parte que constitui três objetos de aprendizagem maiores. Além disso, é o segundo conteúdo de fantasia exógena mais complexo entre os objetos de segundo nível dos quadrinhos gamificados. Este objeto explora um sólido diretamente relacionado com os incidentes da história em quadrinhos. Nele é possível observar a aplicação e planificação da escada, além de possibilitar ao aluno e exploração deste objeto, como apresentado no quinto objeto de aprendizagem do segundo nível.

Este objeto é divido em três partes básicas, onde as duas primeiras exploram diferentes sólidos de escada, aplicados em um triedro e uma épura - quadros 16 e 17 da figura $1-$, e a terceira possibilita que $o$ aluno possa explorar, construindo e desconstruindo a aplicação do sólido, dos segmentos de retas e das projeções nos diferentes planos - quadro 22.

Ao analisar a estrutura do objeto completo percebese que:

- se encontram conteúdo do domínio em quadros da primeira parte da história, explorando a fantasia endógena; e nos quadros dos links, fantasia exógena. Onde, no segundo caso, determinados links contemplam um mesmo conteúdo de formas diferentes, explorando assim a granularidade, onde um objeto intermediário é formado por outros menores;

- a segunda parte da história contempla um link com fantasia exógena, onde o conteúdo de domínio é tratado, também, de várias formas nesse conjunto de quadros. A característica desta parte do objeto de aprendizagem é que o mesmo conteúdopodeser acessado em diferentes pontos;

- a terceira parte não contempla conteúdo de domínio inédito, mas permite o acesso ao último link da primeira parte da história.
De forma geral, o objeto de aprendizagem em história em quadrinhos gamificada apresenta três níveis de granulação, onde o primeiro é formado por cinco objetos diretamente relacionados com exercícios; o segundo nível é formado por sete objetos que formam os maiores e são constituídos por menores; e o terceiro nível formado por dezoito objetos de aprendizagem, que representam a base do artefato.

\section{As Estratégias de Gamificação no Objeto de Aprendizagem}

Os elementos de gamificação utilizados para construir o objeto de aprendizagem em histórias em quadrinhos hipermídia gamificado, utiliza como base a proposta de Domínguez et al. (2013), que consiste em investir nas áreas cognitiva, emocional e social dos alunos.

Quanto aspectos cognitivos o objeto explora o aumento gradual dos níveis de aprendizagem do aluno, uma vez que os objetos de aprendizagem dispostos no decorrer do artefato fornecem bases conceituais para que os alunos possam conhecer o domínio de sólidos. O objeto de aprendizagem é estruturado em três Níveis de Dificuldade (LI, GROSSMAN, FITZMARURICE, 2012), onde: 1 . O primeiro nível possibilita ao estudante acesso aos conteúdos de domínio que auxiliam no entendimento do conceito de sólidos; 2. O segundo nível explora a aplicação de sólidos; 3. O terceiro nível é exigido maior conhecimento do domínio.

Identifica-se que o primeiro nível utiliza a mecânica Integração (ZICHERMANN, CUNNINGHAM, 2011), uma vez que busca fornecer ao estudante conhecimento necessário para a imersão no objeto, apresentando as regras e a narrativa. Da mesma forma a primeira parte do objeto contempla a apresentação da trama (FIELD, 2009), que de forma geral, também fornece informações para o indivíduo possa compreender na história. A característica de certa liberdade de movimentação no objeto, que relaciona o conteúdo de domínio em vários contextos da história, além das possibilidades de recuperação de erros nas atividades, denota a Sensação de Controle que o aluno tem ao interagir com o artefato. Nesse aspecto Murray (2003) coloca que as várias possiblidades de caminhos em uma narrativa não linear dispõem, possibilitam uma maior interação do indivíduo com o artefato digital. Além disso, a Sensação de Controle está associado a categoria estética Agência (MURRAY, 2003) que abrange aquele resultado esperado em uma ação do indivíduo na narrativa. Isso aumenta a capacidade de imersão, e uma vez imerso, a aprendizagem das regras e elementos do novo universo se torna mais fluida. 
A relação entre as partes da história, conteúdos de domínio e exercícios foi construída com base no Crescimento Contínuo de Habilidades (LI, GROSSMAN, FITZMARURICE, 2012), onde, ao passo que o aluno acessa o próximo nível, os exercícios são mais complexos, exigindo assim a aquisição de conhecimento de sólidos pelo estudante. Além disso, os exercícios são construídos com base em Desafios $e$ Missões (IBIDEM), uma vez que cada atividade é um desafio contextualizado pela história. À medida que o aluno vai conhecendo o conteúdo de sólidos e progredindo na história, o nível de dificuldade dos exercícios aumenta. Uma das características das atividades é a forma de Feedback dada as respostas erradas. Como o aluno tem a possibilidade de rever o conteúdo e responder novamente, isso favorece o crescimento do conhecimento.

Sobre os aspectos Emocionais, a contextualização dos Feedbacks das respostas erradas leva a continuações da história buscando manter a imersão do aluno na trama, e possibilitando que o aluno reveja o conteúdo e refaça as atividades impactando a motivação do estudante. Além disso, os três Níveis que compõem os aspetos cognitivos, também contribuem para os aspectos emocionais. Seguindo a base de Field (2009) a história é dividida em três atos, que correspondem: o I Ato a jornada dos piratas até a ilha; II Ato a confrontação propriamente dita, e onde os piratas devem se separar e seguir caminhos sozinhos; III Ato contempla a resolução da história, onde os piratas se reencontram e descobrem o tesouro.

A área emocional está relacionada com as experiências que o indivíduo tem ao interagir com o objeto de aprendizagem. Neste caso o objeto investe na construção de Situações Fantasiosas (KAPP, 2012) como mídia para que o aluno possa explorar a aprendizagem. Isso se traduz na própria construção da história em quadrinhos que traz a trama dos piratas em busca do tesouro. Esse aspecto apresenta como vantagem cognitiva a possibilidade de se explorar metáforas e analogias dentro do mundo ficcional, auxiliado o aluno na compressão de conceitos abstratos e suas aplicações. Como, por exemplo, a relação do mapa do pirata no formato de uma épura, que se transforma em triedro e da ilha como um sólido. Como vantagem emocional, o aluno ao imergir em uma história participativa, percebe sentido no novo conhecimento e se sente motivado a apreendê-lo para que consiga vivenciar a experiência narrativa na busca pelo tesouro.

Explora também a Curiosidade (KAPP, 2012). Além do envolvimento com o próprio conteúdo da história, que gera a ânsia em acompanhar os desfechos dos incidentes. Além dos Feedbacks nas atividades, que levam a possíveis continuações da trama, fornecendo uma variedade de informação atreladas ao conteúdo de domínio que instigam a exploração por parte do indivíduo. Outros aspetos, se traduzem no formato de comandos que levam aos links com conteúdo de aprendizagem, além dos possíveis caminhos que os personagens podem tomar pela não linearidade. Esses tópicos estão relacionados com as Curiosidades Sensoriais. Por outro lado, os incidentes causados pelas respostas erradas nos desafios, envolvem a Curiosidade Cognitiva, uma vez que o aluno percebe que precisa do conhecimento para continuar, e assim ao buscar aprender tem condições de selecionar a resposta correta.

A estruturação do objeto de aprendizagem em uma história fantasiosa, afeta consideravelmente o aspecto emocional do indivíduo, agregando assim na sua motivação. Os Desafios estão incorporados ao objeto, através da dinâmica de navegação e leitura da história, que depende da ação do aluno na obtenção do conhecimento e resposta das atividades. Além disso os Desafios denotam a Recompensa, que é a própria continuação de leitura do objeto até seu desfecho. Segundo Murray (2013), os desafios no decorrer da trama contribuem para aumentar a imersão do aluno. De forma análoga, Zichermann e Cunningham (2011) apontam que tanto a narrativa como as mecânicas de interação na trama estimulam o crescimento dos níveis de engajamento do aluno. Simões, Redondo e Lilas (2013) identificam que aspectos da gamificação incorporados em objetos de aprendizagem como Repetição de Experiências e Possibilidades de Percorrer Caminhos Distintos estão no objeto proposto através dos aspectos da construção da narrativa não linear. A Repetição de Experiências se traduz na redundância de conteúdo de domínio ao longo dos objetos de aprendizagem granuladas, além da possibilidade de o aluno seguir três diferentes caminhos no segundo nível do artefato. Esse mesmo aspecto caracteriza a Possibilidade de Percorrer Caminhos Distintos, pois o indivíduo pode acompanhar a história e realizar a aprendizagem, através daquele personagem que mais se identifica. Além disso, esta dinâmica está presente nos acessos aos links com conteúdo do domínio ao longo de diferentes pontos no objeto. Como por exemplo, em quadros da história durante a execução de uma atividade - desafio. O Mistério é outra característica imposta na construção da trama, e se relacionado com os Desafios no decorrer da história. A incerteza causada pelos possíveis desfechos, interferindo de forma significativa nas ações dos personagens, além de, principalmente no terceiro nível, a dúvida sobre a descoberta do tesouro mantém um clima de suspense com relação a história. Essa mecânica, que investe na busca pelo desconhecido, interfere não penas no grau de motivação do aluno, mas também no seu engajamento de aprender mais sobre o domínio, e assim explorar o objeto de aprendizagem.

O aspecto Social está caracterizado pela possibilidade de o aluno interagir com outros indivíduos ao longo da leitura do objeto. Neste caso, pode-se ex- 
plorar o objeto através da interação com outro, discutindo-se possibilidades e caminhos que passaram despercebidas ou desinteressantes para algum aluno. Além das discussões favorecem o entendimento de algum tópico que por ventura não tenha sido entendido. Essa socialização pode promover a Concorrência entre os indivíduos que estiverem utilizando o objeto no mesmo momento. Entretanto, por não se utilizar placares e rankings, a concorrência está focada na capacidade de exploração do objeto, e conhecimento das possibilidades da narrativa, tornado a relação uma experiência divertida.

Com base nas características essenciais de jogos, apresentadas por Vianna et al. (2013), identifica-se que o objeto de aprendizagem apresenta a leitura da história e a aprendizagem do conceito de Sólidos como uma meta clara e objetiva. As interações do aluno no decorrer da narrativa - leitura da história, aprendizagem e resolução das atividades - são objetivos a serem alcançados para que se atingir esta Meta; as Regras são reveladas pela forma de navegação na história, podendo o aluno optar por ver os quadros da trama e links, como para seguir os percursos dos personagens individualmente. Além disso, na execução das atividades, o aluno entende que ao errar uma questão este ato interfere diretamente o curso da história. Entretanto, há a possibilidade de o aluno aprender com o erro e refazer o exercício.

Murray (2013) identifica que em um meio interativo, a forma de interpretação da narrativa está embutida na estrutura de regras por onde o sistema funciona e no modo pelo qual a participação do usuário é modelada. Esse item corrobora com o sistema de Feedback, onde a história é utilizada como mídia para motivar a aprendizagem do conteúdo de Sólidos. Desse modo, os Feedbacks nas respostas levam à leitura de continuidades específicas da trama. Isso possibilita a construção de uma história ímpar para o aluno, o que consequentemente afeta seu processo de aprendizagem. Quanto à Participação Voluntária, observa-se que a utilização de narrativa em histórias em quadrinhos hipermídia é um fator que motiva a participação do aluno no processo de aprendizagem (GERDE, FOSTER, 2008, SHORT, REEVES, 2009; HUGHES, KING, 2010; BUSARELLO, 2011). No caso dos quadrinhos criados, a história auxilia na interpretação e exemplificação de um conteúdo que pode parecer abstrato aos alunos.

De forma geral, o objeto em história em quadrinhos gamificada investe no Reconhecimento de Padrões, tanto na construção dos comandos de navegação, quando na disposição dos quadros e na dinâmica da execução dos exercícios. Além disso há o elemento de Surpresa na sequencialidade dos quadros que constroem a narrativa, além do Reconhecer para Realizar, que diz respeito na forma como os desafios utilizam do conhecimento adquirido ao longo da história, e sua influência na navegação.
Por fim, a forma de interação que uma narrativa hipermidiática possibilita, favorecendo ao indivíduo uma participação na construção na trama que está lendo (MURRAY, 2003), vai de encontro ao conceito de Viver a História (COLLANTES, 2013), uma vez que o aluno tem uma participação mais ativa no desenrolar da história. O estudante pode a se colocar, mais intensamente, no lugar de um personagem. Estes aspectos correspondem ao colocado por Schmitz, Klemke e Specht (2012) onde o objeto criado investe na construção de personagens, competindo e agindo com seus incidentes e respeitando regras estabelecidas do universo ficcional criado.

\section{Considerações Finais}

O objetivo deste capítulo foi apresentar aconstrução de objeto de aprendizagem em história em quadrinhos gamificado, desenvolvido pelo autor. A partir do grafo que ilustra o mapa de navegação do objeto de aprendizagem, pode-se constatar uma linha que apresenta a história ficcional e lúdica que suporta o artefato. Atrelado a este, encontram-se os links com conteúdo de domínio, além dos exercícios, que compõem tanto ferramenta de aprendizagem, como navegação e leitura da história.

Dividido em três níveis, a primeira parte da história tem a prioridade de introduzir o aluno tanto no conteúdo de aprendizagem, como na história. O segundo nível explora possiblidades para a aprendizagem, traduzido pela separação dos piratas, o que favorece aos alunos terem a experiência do mesmo conteúdo de formas distintas. O terceiro nível se distingue pela finalização da trama, e contemplação da aprendizagem. Como a maior parte dos conteúdos de domínio estão posicionados no primeiro nível, há a possiblidade destes serem acessados em determinadas sequências nos segundo e terceiro níveis.

Como objeto de aprendizagem, o artefato, está divido em três níveis, onde: o primeiro apresenta cinco objetos que finalizam em exercícios; o segundo que diz respeito à sete conteúdos endógenos e exógenos que apresentam o domínio de sólidos e relacionados; e o terceiro que são dezoito objetos menores, básicos. Quanto a gamificação, o objeto apresenta características que investem nos aspectos cognitivos, emocionais e sociais dos alunos. Dentro de cada aspecto apresenta mecânicas e dinâmicas que contribuem para isso, onde: 1. Área Cognitiva explora Níveis de Dificuldade, Integração, Controle, Crescimento Contínuo de Habilidades, Feedback e Desafios e Missões; 2. Área Emocional explora Situações Fantasiosas, Feedbacks, Curiosidade, Desafios, Recompensa, Repetição de Experiências, Possibilidades de Percorrer Caminhos Distintos e Mistério; 3. Área Social explora Socialização e Con- 
corrência. Além disso, há aspectos gerais que também dizem respeito a estratégias de gamificação no objeto de aprendizagem, são: Metas, Regras, Feedback, Participação Voluntária, Reconhecimento de Padrões, Surpresa/Reconhecer para Realizar e Viver a História.

\section{Referências}

AMORY, A., NAICKER, K., VINCENT, J., ADAMS, C. (1999). The use of computer games as an educational tool: identification of appropriate game types and game elements (Vol; $30 \mathrm{~N}^{\circ} 4, \mathrm{p}$. 311-321). British Journal of Educational Technology.

BUSARELLO, R. I. (2016). Gamificação em histórias em quadrinhos hipermídia: diretrizes para construção de objeto de aprendizagem acessível. Tese para obtenção do título de Doutor no programa Pós Graduação em Engenharia e Gestão do Conhecimento - PPEGC, da Universidade Federal de Santa Catarina. Florianópolis.

BUSARELLO, R. I. Geração de conhecimento para usuário surdo baseada em histórias em quadrinhos hipermidiáticas. (2011). Dissertação apresentada para a obtenção ao título de Mestre no Programa de Pós-graduação em Engenharia e Gestão do Conhecimento, área Mídia e Conhecimento, da Universidade Federal de Santa Catarina. Florianópolis, SC.

BUSARELlO, R. I., FADEL, L. M., ULBRICHT, V. R., BIEGING, P. (2014). Construction Parameters for Hypermedia Comics to Learning Based on the Gamification Concept. (v.1. p.616 622). In: International Conference on Design and Emotion (9th : 2014 : Colombia), 2014, Bogotá. The colors of care : 9th International Conference on Design \& Emotion. Bogotá - Colômbia: Ediciones Uniandes.

BUSARELLO, R. I., ULBRICHT, V. R. (2014). A experiência da aprendizagem para surdos através de quadrinhos hipermídia: abordagem sobre o processo de aprendizagem acessível (v.1, p. 129144). In: Práticas e geração de conhecimento frente às novas mídias.1 ed.São Paulo : Pimenta Cultural.

COLLANTES, X. R. Juegos y viedojuogos. Formas de vivencias narrativas.(2013). In SCOLARI, Carlos A.. Homo Videoludens 2.o. De Pacman a la gamification. Col-leccio Transmedia XXI. Laboratori de Mitjans Interactius. Universitat de Barcelona. Barcelona.

CRAVEIRINHA, R., ROQUE, L. (2010). Drama Online: a New Interactive Narrative Model designed for Online Play. PRISMA.COM n. ${ }^{ } 10$ - Especial Videojogos20o9 ISSN: 1646 - 3153.

DE-MARCOS, L., DOMÍNGUEZ, A., SAENZ-DE-NAVARRETE, J., PAGÉS, C. (2014). An empirical study comparing gamification and social networking on e-learning (p. 82-91). Elsevier. Computers \& Education 75.

DOMínguEZ, A., NAVARRETE, J. S., MARCOS, L., SANZ, L. F. PAGÉS, C., HERRÁIZ, J. J. M. Gamifying learning experiences: Practical implications and outcomes. Journal Computers \& Education, Virginia, v. 63, p. 380-392, 2013. 
FIELD, S. Roteiro: os fundamentos do roteirismo (2009). Curitiba : Artes e Letras.

GERDE, V. W., FOSTER, R. S.. X-Men Ethics: Using Comic Books to Teach Business Ethics.(2008). DOI 10.1007/s10551-006-9347-3. Journal of Business Ethics 77:245-258.

GARRIS, R., AHLERS, R., DRISKELL, J. E. Games, Motivation, an Learning: a research and practice model. Simulation \& Gaming, Vol. 33 No. 4, December, 2002. 441-467.

HANUS, M. D., FOX, J. Assessing the effects of gamification in the classroom: A longitudinal study on intrinsic motivation, social comparison, satisfaction, effort, and academic performance. Computers \& Education 80 (2015) $152 e 161$.

HUGHES, J., KING A. E. Dual Pathways to Expression and Understanding: Canadian Coming-of-Age Graphic Novels. DOI 10.1007/s10583-009-9098-8. Children's Literature in Education (2010) 41:64-84.

KAPP, K. M. The gamification of learning and instruction: Game-based methods and strategies for training and education. San Francisco: Pfeiffer, 2012.

LI, W., GROSSMAN, T., FITZMAURICE, G. Gamified Tutorial System For First Time AutoCAD Users. UIST '12, October 7-10, 2012, Cambridge, Massachusetts, USA.

MACEDO, C. M. S. Diretrizes para criação de objetos de aprendizagem acessíveis. Tese para obtenção do título de Doutor no programa Pós Graduação em Engenharia e Gestão do Conhecimento - PPEGC, da Universidade Federal de Santa Catarina. Florianópolis, 2010.

MCGREAL, R. and ELLIOT, M. Technologies of On-line Learning (e-learning). in Theory and Practice of On-line Learning. (S.l.): Athabasca University, v. 1, 2004. Cap. 5, p. 115-135.

MCCLOUD, S. Reinventando os Quadrinhos: como a imaginação e a tecnologia vêm revolucionando essa forma de arte. M. Books do Brail Editora Ltda. - São Paulo : 2006.

MURRAY, J. H. Hamlet no holodeck: o futuro da narrativa no ciberespaço. São Paulo: Itaú Cultural: Unesp, 2003 .

NUNES, E. V., BUSARELLO, R. I., DANDOLINI, G.; SOUZA, J. A., ULBRICHT, V. R, VANZIN, T. Construção de objetos de aprendizagem acessível: foco na aprendizagem significativa. Cadernos de Informática - Volume 6 - Número 1 - 2011. Anais do VI Congresso Ibero-americano de Telemática (CITA 2011) - Gramado RS (Brasil), 16-18 Maio 2011.

SCHMITZ, B., KLEMKE, R., SPECHT, M. Effects of mobile gaming patterns on learning outcomes: a literature review. Journal Technology Enhanced Learning, 2012.

SHORT, J. C.; REEVES, T. C. The Graphic Novel: a "cool” format for communicating to generation Y. DOI: 10.1177/1080569909336464 Business Communication Quarterly 2009 72: 414. 
SIMÕES, J; REDONDO, R D; VILAS, A F. A social gamification framework for a K-6 learning platform. Computers in Human Behavior. Instituto Superior Politécnico Gaya, Portugal: [s.n.]. 2012.

VIANNA, Y., VIANNA, M., MEDINA, B., TANAKA, S. Gamification, Inc.: como reinventar empresas a partir de jogos. MJV Press : Rio de Janeiro, 2013.

WILEY, D. A. Connecting Learning Objects to Instructional Design Theory - a definition, a methaphor and a taxonomy In: The Instructional Use of Learning Objects. Utah: [s.n.]. 2000.

ZICHERMANN, G.; CUNNINGHAM, C. Gamification by Design: Implementing Game Mechanics in Web and Mobile Apps. Sebastopol, CA : O’Reilly Media, Inc. 2011 